\title{
A ciência de serviço e algo de um legítimo admirável mundo novo
}

Ricardo Teixeira Veiga

Professor Titular do Departamento de Ciências Administrativas da Faculdade de Ciências Econômicas da UFMG. Coordenador do NECC (Núcleo de Estatística e Ciências Comportamentais). Graduado em Ciência da Computação, Especialista em Estatística, Mestre e Doutor em Administração pela UFMG. Bolsista de Produtividade do CNPq, Minas Gerais, Brasil.

ricardo.necc@gmail.com

André Torres Urdan

Docente da Universidade Nove de Julho. Foi professor titular da Escola de Administração de Empresas de São Paulo da Fundação Getúlio Vargas (EAESPFGV), doutor da Universidade de São Paulo e adjunto da Universidade Federal de Minas Gerais. Doutor (Universidade de São Paulo) e Mestre em Administração (EAESP-FGV). Graduado em Engenharia, (Universidade Federal de Minas Gerais), Ciências Contábeis (Pontifícia Universidade Católica de Minas Gerais) e Administração (Universidade Federal de Minas Gerais), São Paulo, Brasil andre.urdan@gmail.com

Editor Científico: José Edson Lara Organização Comitê Científico

Double Blind Review pelo SEER/OJS

Recebido em 04.12.2017

Aprovado em 18.12.2017

\section{(c) (1) (8)}

Este trabalho foi licenciado com uma Licença Creative Commons - Atribuição - Não Comercial 3.0 Brasil 


\title{
Resumo
}

Complexas demandas de mercado e da sociedade levam empreendedores inovadores a lançar empresas baseadas no conhecimento, que mudam o modo de vida de muita gente. Novos modelos de negócios vão tirando proveito do crescimento das internets e da computação em nuvem, entre tantas possibilidades impulsionadas pela tecnologia. No círculo acadêmico, subjacente a essas transformações, emergiu a Lógica Dominada por Serviço (LDS), uma filosofia de marketing e gestão, fruto da colaboração de professores, pesquisadores, consultores e profissionais. Diante da proliferação de subdisciplinas no Marketing, típica de uma crise de paradigma, Vargo e Lusch (2004) propuseram um arcabouço estruturante da teoria de Marketing, calcada em elegante e parcimonioso conjunto de axiomas, premissas e conceitos. A LDS abriu avenidas de progresso teórico e metodológico, com interessantes implicações práticas. Indo além, a LDS é o esteio da emergente Ciência de Serviço. Nessa órbita, este artigo expõe e reflete sobre a Ciência de Serviços e seu entorno; apresenta as razões, a natureza e os impactos da Ciência de Serviço; sintetiza a LDS; explica a Internet das Coisas e as organizações baseadas em conhecimento; mostra a vanguarda da IBM nessa jornada; realça a pertinência dessa Ciência para o Brasil e estimula a adoção prática dessas perspectivas e da contribuição acadêmica para a evolução delas.

Palavras-chave: Ciência de Serviço; lógica dominada por serviço; sistemas de serviço; nova economia.

\section{The science of service and something of a legitimate admirable new world}

\begin{abstract}
Complex market and society demands lead entrepreneurs to launch innovative knowledge-based firms, that change the way of life of many people. New models of business are taking advantage of the growth of the Internets and cloud computing, among so many technology-driven opportunities. In the academic circle, underlying these transformations, emerged the Service Dominant Logic (SDL), a marketing and management philosophy, fruit of the collaboration of teachers, researchers, consultants and professionals. Given the proliferation of sub-disciplines in Marketing, typical of a paradigm crisis, Vargo and Lusch (2004) proposed a structuring framework for Marketing theory, based on a elegant and parsimonious set of axioms, assumptions, and concepts. The SDL opened avenues of theoretical and methodological progress, with interesting practical implications. Going beyond, the LDS is the mainstay of the emerging Science of Service. In this orbit, this article exposes and reflects on the Science of Service and its surroundings. Presents reasons, nature and impacts of Science of Service. Synthesize the SDL. Explains the Internet of Things and the knowledge-based organizations. Shows the forefront of IBM on this journey. Highlights the relevance of this science to Brazil. Stimulates the
\end{abstract}


practical adoption of these perspectives and the academic contribution to the development of them.

Keywords: Science of service; service-dominant logic; service systems; new economy.

\section{La ciencia de servicio y algo de un legítimo admirable mundo nuevo}

\section{Resumen}

Las complejas demandas de mercado y de la sociedad llevan a emprendedores innovadores a lanzar empresas basadas en el conocimiento, que cambian el modo de vida de mucha gente. Los nuevos modelos de negocio van aprovechando el crecimiento de los internets y de la computación en nube, entre tantas posibilidades impulsadas por la tecnología. En el círculo académico, subyacente a estas transformaciones, surgió la Lógica Dominada por Servicio (LDS), una filosofía de marketing y gestión, fruto de la colaboración de profesores, investigadores, consultores y profesionales. En cuanto a la proliferación de subdisciplinas en el Marketing, típica de una crisis de paradigma, Vargo y Lusch (2004) propusieron un marco estructurante de la teoría de Marketing, calcada en elegante y parcimonioso conjunto de axiomas, premisas y conceptos. La LDS abrió avenidas de progreso teórico y metodológico, con interesantes implicaciones prácticas. Además, la LDS es el centro de la emergente Ciencia de Servicio. En esta órbita, este artículo expone y refleja sobre la Ciencia de Servicios y su entorno; presenta las razones, la naturaleza y los impactos de la Ciencia de Servicio; sintetiza la LDS; explica la Internet de las Cosas y las organizaciones basadas en el conocimiento; muestra la vanguardia de IBM en esta jornada; destaca la pertinencia de esta Ciencia para Brasil y estimula la adopción práctica de esas perspectivas y de la contribución académica para la evolución de ellas.

Palabras clave: Ciencia de servicio; lógica dominada por servicio; sistemas de servicio; nueva economía.

\section{Introdução}

Na década de 1970, Bell (1978) cunhou a expressão sociedade pós-industrial para designar a estruturação social que começava a se manifestar nas nações mais desenvolvidas. Passava-se de uma dominância da produção de bens para uma economia em que preponderavam serviços. Se na sociedade industrial, segundo ele, o principal recurso era o capital, na pós-industrial o recurso central seria o humano e o fator mais relevante seria a organização da ciência. 
Décadas depois, a economia de serviço deu um salto a partir da junção de globalização e digitalização. Desses fenômenos resultam empresas modernas, com fronteiras mutáveis, portfólio flexível de serviços, que intensivamente empregam informação e suas tecnologias, respondendo agilmente às condições de mercado e do ambiente todo (Katzan Jr., 2008). O sucesso das empresas baseadas no conhecimento - como a Salesforce.com (software \& programação para vendas e marketing) e a Netflix (distribuição de conteúdo pela internet) - liga-se a mudanças

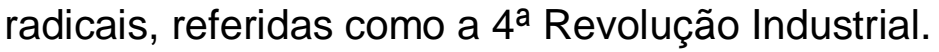

Mais e mais produtos inteligentes serão lançados, como um pneu que notifica o motorista da sua pressão de ar e uma peça de roupa que aquece ou esfria em resposta às mudanças de temperatura, a raquete de tênis que brilha onde ela bate na bola. São produtos inteligentes porque interpretam dados para habilitar o usuário a agir de forma mais eficaz (Davis \& Botkin, 1994). Suas características incluem interatividade, se tornarem mais espertos à medida que o consumidor os usa e a capacidade de personalização.

Os impactos econômicos da $4^{a}$ Revolução Industrial, na análise da consultoria Accenture em 2015, serão positivos e negativos. Estima-se a preocupante extinção de cinco milhões de postos de trabalho nos 15 países mais industrializados, mas também a agregação de US\$14,2 bilhões à economia mundial nos 15 anos seguintes (Perasso, 2016), montante não tão alto, mas que tende a um crescimento acelerado. Prevê-se a ampliação global dos níveis de rendimento e a melhora da qualidade de vida de populações inteiras, incluídos os países menos desenvolvidos. São efeitos dessa nova etapa revolucionária ao alargar o acesso a serviços e bens e trazer novos estilos de trabalho e de vida (Schwab, 2016).

Haverá mais e mais pro consumidores (que produzem e consomem) em toda parte, aduz Rifkin (2014), em vista da crescente capacidade de conectar, produzir e partilhar bens, serviços e energia em um rede global colaborativa, a custos marginais baixos ou próximos de zero. A factibilidade dessa jornada já se mostra, aqui e agora, no Brasil: a) na impressão 3D, a ensejar a produção de um objeto modelado na tela do computador e um alto poder de personalização sem afetar o custo (Capelas, 2017): b) nos Fab Labs, espaços abertos de criatividade, aprendizado e inovação, com disponibilidade de equipamentos e outros recursos para compartilhamento, para quem queira desenvolver e construir objetos, em 
diferentes escalas, seja para si, seja para transformar uma ideia em negócio (Sawada, 2016).

Por outro lado, os complexos problemas inerentes aos contemporâneos ecossistemas de serviço reclamaram e impulsionaram a propositura de uma nova ciência, que substitua a fragmentação e o reducionismo analíticos tradicionais e proporcione eficácia, eficiência e sustentabilidade. Eis a Ciência de Serviço. Afinal, pouco adiantaria seguir abordando os sistemas de serviço com métodos e técnicas de uma ou outra das disciplinas que já o contemplavam, como Marketing, Operações, Recursos Humanos, Tecnologia de Informação. Essa empreitada reclama uma disciplina própria, que reúna e integre diversas disciplinas, erigindo um referencial que cubra os variados contextos e condições desses sistemas, num arranjo de feição, mais que multidisciplinar, interdisciplinar (Maglio, 2013). A Interdisciplinaridade envolve a integração de perspectivas, teorias e técnicas de duas ou mais disciplinas, enquanto a multidisciplinaridade se pauta pela adição dos subsídios dessas disciplinas.

Nesse contexto, o objetivo geral deste artigo é expor e refletir sobre a Ciência de Serviços e seu entorno. Almeja-se, em desdobramento: a) apresentar as razões, a natureza e os impactos da Ciência Serviços; b) explicar a Internet das Coisas e o trunfo das organizações baseadas em conhecimento; c) sintetizar a base filosófica dessa Ciência, a Lógica Dominada por Serviço; d) realçar a especial pertinência dessa Ciência para o Brasil. Não se trata de algo fácil de ser atingido, como à primeira vista pode parecer. Cabe aqui, em certo grau, o alerta de um astrônomo e célebre divulgador da Ciência: "Vivemos em uma sociedade absolutamente dependente da ciência e tecnologia e, todavia, organizamos inteligentemente as coisas para que quase ninguém compreenda a ciência e a tecnologia. Isso é uma clara receita para o desastre" (Sagan, 2006, p. 100).

\section{Internet das Coisas}

No caminhar da 4⿳亠丷a Revolução Industrial, sistemas ciberfísicos vão integrando robôs, computadores e linhas de produção, em fábricas e artefatos autônomos, se aproveitando da convergência de tecnologias digitais, físicas e biológicas (Schwab, 2016). Um sistema ciberfísico combina máquinas com processos digitais, tomando decisões descentralizadas e com cooperação entre seus componentes e com 
pessoas, potencial que se viabiliza pela combinação da Computação em Nuvem com a Internet das Coisas.

$\mathrm{Na}$ Computação em Nuvem emprega-se a capacidade de armazenamento e de processamento de computadores e servidores compartilhados via Internet, seguindo o princípio da computação em grid, que logra alta taxa de processamento ao dividir tarefas entre diversas máquinas, em rede local ou de longa distância (Erl, Puttini, \& Mahmood, 2013). Trata-se de uma coleção de máquinas virtuais, em que processos a um tempo demandados por um usuário são executados em máquinas que se encontram ociosas, ociosidade que decorre de outros usuários que não estão delas necessitando. Ao longo do tempo, vão se intercambiando os usos e não usos da capacidade instalada, numa produtividade bastante superior dos recursos computacionais. Indo além, muitas são as serventias da computação em nuvem: criar novos aplicativos e serviços, armazenar, fazer backup e recuperar dados, hospedar sites e blogs, movimentar fluxos de áudio e vídeo, entregar software sob demanda, analisar dados em busca de padrões e para fazer previsões (Microsoft Azure, 2017). Ao lado estão as expressivas vantagens da computação em nuvem: custo, produtividade, velocidade, confiabilidade, escala global.

Já espraiada pelo Mundo, a Internet da Comunicação vai convergindo, com o despontar das Internets da Energia e da Logística, abrindo uma plataforma tecnológica que propende a conectar tudo e todos (Kellmereit \& Obodovski, 2013). Incontáveis sensores ${ }^{1}$ são mais e mais inseridos em recursos naturais, prédios, máquinas, linhas de produção, redes elétricas e de logística, casas, escritórios, lojas, veículos e até mesmo os seres humanos. Conectados esses nós, se cria a capacidade de coletar, armazenar e transmitir dados, numa colossal base de dados, que deve culminar com uma rede global de Internet das Coisas. Isso, descreve Rifkin (2014), traz consigo uma era de bens e serviços quase gratuitos. A formidável infraestrutura de tecnologia da Internet das Coisas pode empurrar categorias de bens e serviços para um custo marginal baixíssimo nos próximos anos. As pessoas já se acostumaram com a gratuidade na obtenção de tantos benefícios, como no YouTube ou Facebook. Tempos atrás, soluções análogas eram regidas pela

\footnotetext{
${ }^{1}$ Sensor é um dispositivo que responde a estímulos físicos (calórico, luminoso, sonoro, pressional, magnético, motor) e transmite um impulso correspondente (Houaiss, 2009).
} 
economia da escassez. O consumidor teria de pagar os custos e o lucro de um disco, CD ou DVD e das ligações telefônicas e postagens de cartas.

Emblemática dessa onda, a Google prospera com a sinergia gerada pela gestão de um amplo portfólio de serviços, da produção de seus próprios sistemas, equipamentos e acessórios, da compra, e eventualmente venda, de outras empresas, do aluguel e da venda de conteúdo digital na Internet ${ }^{2}$. A Google, gigante de tecnologia, inventou novos modelos de negócios que cresceram vertiginosamente, graças à lealdade de milhões de usuários, atraídos especialmente por serviços gratuitos na internet, como motor de busca (Google.com) e correio eletrônico (Gmail). Ela vende anúncios nas páginas resultantes de buscas, cujo preço varia conforme o destaque e posição do anúncio, com o atrativo, para o anunciante, de selecionar usuários que já manifestaram interesse pelo seu serviço, bem e/ou marca. Há muitos outros serviços prestados pela Google: a rede social Google+, a plataforma para distribuição de vídeos YouTube, serviços corporativos de computação em nuvem, softwares (como aplicativos e o sistema operacional Android, o mais popular para smartphones e tablets) e equipamentos eletrônicos, como o Google Glass. Por tudo isso, a Google lucrou US\$ 75 bilhões em 2015, sendo cerca de $90 \%$ provenientes de comercialização de espaço para propaganda. A corporação Alphabet, proprietária da Google, atingiu valor de mercado de mais de US\$ 500 bilhões, disputando com a Apple a posição de companhia mais valiosa do mundo (BBC, 2016).

\section{Ciência de Serviços e Logica Dominada por Serviço}

A humanidade, como nunca na História, precisa de um planeta mais inteligente, que possa manter e aprimorar - de forma sustentável - a qualidade de vida, conciliando as expectativas de curto prazo com a viabilidade das gerações futuras (Wolfson et al., 2010). Expectativas de um contingente estimado (no momento em que este parágrafo foi escrito) em 7.582.687.824 habitantes da Terra (Worldmeters, 2017). Esse desafio implica sistemas de serviço da mais alta

\footnotetext{
${ }^{2}$ Como na compra da Motorola Mobility, fabricante de dispositivos Android, da startup britânica de inteligência artificial DeepMind e da fabricante de robôs Boston Dynamics (adquirida em 2013 e vendida em 2017, para a empresa japonesa Softbank), aluguel e venda de aplicativos, filmes, músicas, livros e revistas, pelo serviço Google Play.
} 
envergadura e complexidade (Banhe \& Polese, 2010) e sistemas evidentes na atualidade das grandes cidades: abastecimento de água \& tratamento sanitário, geração \& distribuição de energia, transporte urbano, assistência de saúde, entre tantos.

A pesquisa em serviço já vinha pondo em xeque cânones do Marketing, a começar pela concepção do Mix de Marketing (Gummesson \& Mele, 2010), mormente quando deixam de lado o intrincado arcabouço multifacetado que afeta as estruturas e dinâmicas de mercado (em que clientes e fornecedores são apenas dois de vários agentes) e as outras áreas que participam da gestão. Mesmo no tradicional Journal of Marketing, seu editor aponta como "paradigma emergente" para a disciplina a integração nas decisões da organização, mediante articulação com as outras funções do negócio e da Administração e suas numerosas interfaces (Kumar, 2015).

Surge, em resposta a essas perturbações e obstáculos, a Ciência de Serviço. Seu domínio cobre a gestão (desde o projeto até o controle) dos sistemas de serviço, tomados como arranjos de cocriação de valor, reconhecendo seus vários atores e recursos, tais como pessoas, tecnologia, informação e instituições. Sistemas de serviço podem ser tão pequenos quanto alguns indivíduos ou tão grandes quanto a internet. Um sistema desses conecta-se - por meio de proposições de valor - a outros sistemas de serviços internos ou externos (do que são exemplos organizações, unidades organizacionais, cidades e agências governamentais) (Maglio \& Spohrer, 2008).

Aqui, o construto nuclear de um sistema de serviço, o "serviço", não corresponde a produto intangível (em contraposição a produto tangível ou bem) ${ }^{3}$. Serviço é tomado, sob a ótica da Lógica Dominada por Serviço (LDS) (Vargo \& Lusch, 2004), como: a) o processo básico subjacente às trocas; b) a aplicação de habilidades e conhecimentos específicos para o benefício de outra parte. Trocas de serviço são motivadas por proposições de valor em sistemas de valor de diferentes níveis de agregação e complexidade, cujo bloco mais elementar é a troca de serviço

\footnotetext{
${ }^{3} \mathrm{E}$, ainda, bem não estocável, de qualidade heterogênea, cuja produção é simultânea à entrega (Zeithaml, Parasuraman, \& Berry, 1985). As quatro características remetem à tradicional aplicação de uma "lógica dominada por produto", que estimulou a divisão do marketing em subdisciplinas, como o "marketing de serviços". Nessa perspectiva, hoje ultrapassada, produto é compreendido como solução para uma demanda, por exemplo, como produto, uma furadeira é um utensílio que atende à necessidade de fazer furos (Kotler \& Armstrong, 2015)
} 
por serviço numa relação diádica entre atores. Uma troca de serviço envolve divisão de trabalho entre os participantes, baseada em suas especializações e seus recursos complementares, mobilizados para uma cooperação bem-sucedida. $\mathrm{Na}$ LDS, os produtos (bens e serviços) são unidades de saída do processo de serviço. Funcionam como mecanismos de distribuição, nos quais competências e recursos são combinados, resultando em valor singular, considerando-se o ponto de vista específico de cada ator.

Considere-se o caso de um analgésico. Conhecimentos de Bioquímica e tecnologia farmacêutica, bem como sistemas de produção e marketing, são integrados para oferecer ao mercado um medicamento que potencialmente alivia a dor humana, atuando de várias maneiras em seus sistemas nervosos central e periférico. Todavia, a venda e compra de um produto é uma troca e o valor nas trocas é sempre cocriado idiossincraticamente, incluindo necessariamente a contribuição do destinatário (o cliente). Logo, o resultado do medicamento não pode ser garantido pela proposta de valor da indústria farmacêutica que o fornece. $\mathrm{O}$ resultado aí depende do engajamento, da motivação, competência e do envolvimento de outros recursos dos demais atores da troca. No caso do analgésico, a posologia correta deve ser seguida no consumo, caso contrário a droga pode ser ineficaz. E, talvez, os efeitos placebo e nocebo (Scott et al., 2008) sejam as demonstrações mais dramáticas de como os usuários contribuem, mesmo inconscientemente, para a cocriação de valor, quando tomam um analgésico ou outro remédio.

Prossegue-se nessa seara do doente, da patologia e da solução, com vistas a ilustrar o caráter idiossincrático da cocriação de valor. Modelar é o caso de Anneke Westra (Capell, Arndt, Carey, 2005). Aos 30 anos, ela era uma cientista promissora, apesar de longa batalha contra a depressão. Veio o diagnóstico de desordem bipolar; começou uma longa luta pela saúde. Anneke passou por 10 psiquiatras e 18 medicamentos - cada um parecendo ter efeitos colaterais piores que o anterior. Deterioram-se sua saúde mental e física. Hospitalizada frequentemente e incapaz de trabalhar, tentou o suicídio. Aneke considera ter perdido 10 anos de sua vida com os remédios que Ihe prescreveram. O caso de Anneke é extremo, mas não único. Uma em cada cinco pessoas sofre, em algum momento da vida, de depressão grave, o suficiente para exigir terapia medicamentosa. Muitas dessas pessoas passam meses experimentando uma variedade de drogas, em dosagens diferentes, antes de chegar 
a uma que seja efetiva. Para 1 em 4 pacientes, os antidepressivos mais comuns não funcionam. Milhões de outras pessoas padecem com os efeitos colaterais dos medicamentos.

Nas sociedades contemporâneas, mudanças tecnológicas transformaram sistemas fechados, dependentes de contato direto com um cliente, em ecossistemas de negócios abertos e flexíveis, nos quais o valor é construído em cooperação, como resultado do compartilhamento de informação, trabalho, risco, serviços e bens (Maglio \& Spohrer, 2008). Empresas baseadas no conhecimento atuam principalmente no compartilhamento de informações com clientes e parceiros de negócio. Em outros tipos de empresa avulta o compartilhamento de outras dimensões de competência. Um caso é o da Insperity, firma de terceirização de recursos humanos, que oferece soluções calcadas em compartilhamento de trabalho. Seguradoras, como a Porto Seguro, são dominadas pela divisão de riscos, enquanto a locadora de veículos Localiza compartilha bens.

É muito útil utilizar conceitos e um esquema teórico de sistema de serviço, estampado na Figura 1, na descrição de uma organização ou qualquer outra entidade complexa, mostram Lyons e Tracy (2013). Para lidar com as dificuldades de abstração e recursividade do conceito de sistema de serviço, a moldura que eles propõem ajuda a identificar as variáveis de interesse e suas inter-relações que requerem análise, esquema que pode ser especificado, num caso concreto, mediante roteiros de entrevista. Apoiados em Katzan (2008) e Spohrer et al. (2008), Lyons e Tracy (2013) aduzem 10 conceitos fundamentais, inscritos na Figura 1, para a compreensão abstrata de um sistema de serviço: recursos, entidades, direitos de acesso, interações criadoras de valor, interações de governança, resultados, partes interessadas (stakeholders), redes, resultados e ecologia. A essência desses conceitos é exposta a seguir. 


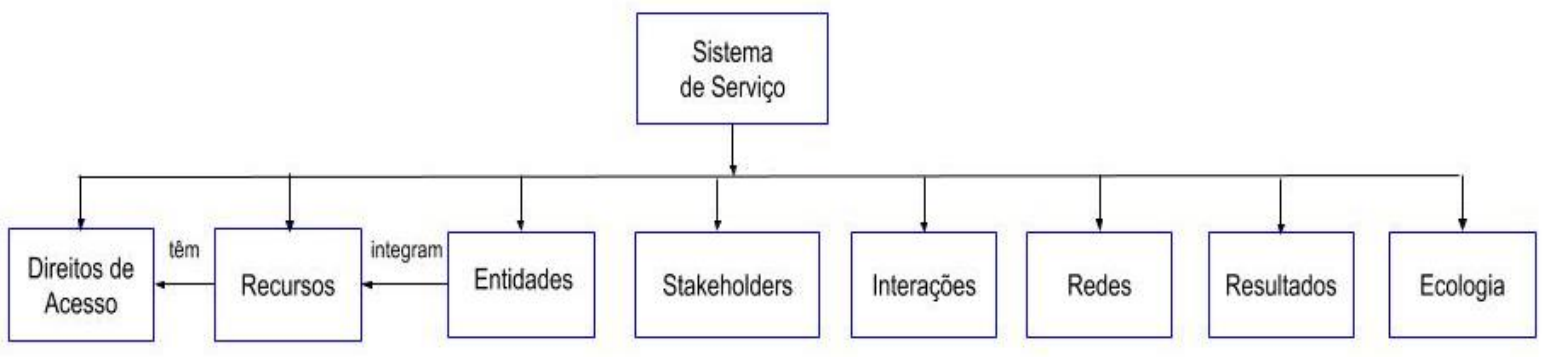

(...) A estrutura se expande verticalmente com a discriminação de componentes dos objetos de segundo nivel (...)

\section{Figura 1}

Uma esquema teórico do sistema de serviço

Fonte: adaptado de Lyons, K. \& Tracy, S. (2013). Characterizing organizations as service systems. Human Factors and Ergonomics in Manufacturing \& Service Industries, 23(1), 19-27.

O sistema de serviço embute uma estrutura hierárquica, na qual os recursos têm papel central, pois são trocados com o propósito de criação de valor. Entende-se a estrutura a partir da identificação dos principais recursos e entidades que a integram. Há recursos operantes e operáveis, segundo Lusch e Vargo (2014). Os operantes, como conhecimentos e habilidades, incluem as competências essenciais da organização. Quatro tipos de recursos-chave são apontados por Maglio e Spohrer (2008): pessoas, tecnologia, organizações e informações compartilhadas (linguagem, normas e medidas). Recursos, em Spohrer et al. (2008), são distinguidos pela sua natureza (físicos ou não) e pelo direito (existente ou inexistente) de acessá-los. Pessoas e computadores, por exemplo, são recursos físicos, mas apenas pessoas têm direitos. O direito de acesso a recursos, que se desdobra em direitos de propriedade e de uso, é um atributo relevante para o design e gestão dos sistemas de serviço.

Entidades são agentes sociais integradores de recursos, via troca de competências. Todas as entidades são recursos, mas o oposto não é verdadeiro (Spohrer et al., 2008). Entidades variam quanto ao seu papel único e sua contribuição para os resultados do serviço. Uma entidade pode ser, por exemplo, dona ou responsável pelo sistema, produtora, provedora do serviço, cliente ou objeto do serviço (Katzan, 2009). Interações de serviços ocorrem entre as entidades, nos processos de mobilização, troca e integração de competências e recursos, para fins de cocriação de valor ou governança do sistema. 
Resultados do serviço podem envolver a efetivação da proposta de valor do sistema, um possível malogro dessa proposta, disputas relativas ao insucesso na concretização do valor, interações não relacionadas à proposta de valor e seu tratamento adequado. Terceiras partes ou stakeholders incluem acionistas, empregados, clientes, fornecedores, locatários e outros membros da sociedade afetados pelo sistema de serviço. Medidas são tipos de informações compartilhadas com a finalidade de cocriação de valor ou governança do sistema de serviço. Entre as medidas frequentes utilizadas estão as de qualidade, produtividade, inovação e sustentabilidade, conformidade legal e as relativas às diferentes perspectivas dos stakeholders (clientes, provedores, autores, concorrentes etc.).

Uma rede constitui-se de nós (em geral esquematicamente representados por pontos) e conexões entre os nós (representados por flechas). Os nós são as partes distintas da rede, ao passo que as conexões são as relações que mantêm as partes entrelaçadas. Redes conectam, penetram e perpassam o sistema de serviço, formando-se em torno das trocas entre entidades, ligando o sistema a recursos e entidades externos, constituindo recursivamente outros sistemas de serviço de diferentes níveis de complexidade e abrangência. Há uma fecunda interdependência entre a Ciência de Serviços e as redes, mormente em um mundo digitalmente integrado. A disseminação da conexão de pessoas e organizações a recursos crescentemente digitalizados, numa cyber-infraestrutura pública em rede, viabiliza que até uma pequena empresa possa manobrar conexões vigentes em sua esfera (Hsu, 2009), nos moldes do extraordinário Google. Por aí, uma empresa pode cobrir desde uma população inteira até às necessidades pessoais, mediante combinações e configurações de sua cadeia de valor.

A Ecologia trata do estudo científico dos modos como organismos interagem entre si e com o seu ambiente físico (Gotelli, 2008). Reconhece que a distribuição e abundância dos organismos na terra são moldadas por fatores tanto bióticos (relacionados a organismos vivos) quanto abióticos (relacionados a organismos inanimados ou físicos). O domínio da Ecologia abrange o ecossistema, como a descrição da rede de relações entre organismos em diferentes escalas (organismo, comunidade, população, biosfera etc.). Dentre as muitas aplicações práticas da Ecologia está a abordagem de fenômenos organizacionais (Hannan \& Freeman, 1989), sendo esta a que interesse ao sistema de serviço. A ecologia das 
organizações realça a diversidade de formas organizacionais, a competição/cooperação por recursos, as taxas de entrada e saída de 'organismos' e os impactos nos destinos de uma organização provocados por forças impessoais e pela intervenção dos indivíduos. Dessa forma, as concepções da Ecologia servem à compreensão do universo de um sistema de serviço e, indo além, de sua interdependência com outros sistemas.

A aplicabilidade do esquema teórico do sistema de serviço (Figura 1) é ilustrada por Lyons e Tracy (2013, p. 6, Tabela 1) com uma biblioteca acadêmica, integrante de um departamento universitário de serviços de informação. Lá eles descrevem os elementos e as capacidades presentes. llumina cientistas de serviço e stakeholders com uma nova perspectiva de design do sistema e de sua governança. Outra aplicação esclarecedora - da organização como sistema de serviço - emana de Basharat e Ahmad (2017). Esses autores delineiam duas organizações de saúde: o Sistema de Cuidado ao Paciente e o Centro de Pesquisa do Hospital Shaukat Khanun (na Índia) e o Hospital Shouldice (no Canadá). Salta aos olhos o poder de descrição e diagnóstico do esquema teórico de sistema de serviço, sobretudo pela perspectiva interativa de entidades, stakeholders, recursos e a integração deles.

Mas vale aqui um alerta no aproveitamento, seja ele científico, seja gerencial, do esquema teórico do sistema de serviço da Figura 1. Provém de um tempo em que a realidade era radicalmente diferente da que hoje circunda a Ciência de Serviço. Lévi-Strauss (1969), no clássico estudo que decifrou 187 mitos Ameríndios, apontava que o cientista é aquele que faz as perguntas certas, não quem apresenta as respostas certas, avanço antropológico que ali partiu das perguntas do célebre antropólogo, mas que se assentou nas respostas daqueles Ameríndios, numa investigação cientificamente acurada. Essa posição proeminente - dada pelo pesquisador a quem ele quer compreender - é similarmente crucial para a evolução da Ciência de Serviço, em linha com a Lógica Dominada por Serviço, cuja proeminência é do cliente e dos outros agentes do sistema de serviço.

Uma visão enriquecida do sistema de serviço se forma com a Lógica Dominada por Serviço (Spohrer et al. 2008). Em sua revisão mais recente, a LDS incorpora 11 premissas fundamentais, listadas na Figura 2, sendo cinco delas axiomas das quais as demais derivam (Vargo \& Lusch, 2016). 
(P1, axiomática): Serviço é a base fundamental da troca.

Premissas derivadas:

$(\mathrm{P} 2)$ : Trocas indiretas escondem a base fundamental de troca.

(P3): Bens são mecanismos de distribuição de serviços.

(P4): Recursos operantes são as fontes fundamentais de benefício estratégico.

(P5): Todas as economias são economias de serviço.

(P6, axiomática): Valor é cocriado por múltiplos atores, sempre incluindo o beneficiário.

Premissas derivadas:

(P7): Atores não podem entregar valor, mas podem participar na criação e oferta de propostas de valor.

(P8): Uma visão centrada em serviço é inerentemente orientada para o beneficiário e relacional.

(P9, axiomática): Todos os atores, sociais e econômicos são integradores de recursos.

(P10, axiomática): Valor é única e fenomenologicamente determinado pelo beneficiário.

(P11, axiomática): A cocriação de valor é coordenada via instituições geradas pelos atores e arranjos institucionais.

\section{Figura 2}

Premissas Fundacionais da Lógica Dominada por Serviço

Fonte: Vargo, S. L., \& Lusch, R. F. (2016). Institutions and axioms: an extension and update of service-dominant logic. Journal of the Academy of Marketing Science, 44(1), 5-23.

O conjunto de premissas fundacionais da LDS (Figura 2) representa um novo paradigma para as trocas no Marketing e possivelmente para todas as trocas sociais, servindo de base para uma teoria geral de marketing (Lusch \& Vargo, 2014). O primeiro axioma enfatiza o conceito de serviço como essência das trocas e da Economia. O segundo postula que o valor do serviço é cocriado por múltiplos atores, incluindo sempre o beneficiário. $O$ terceiro axioma aponta que todos os atores são integradores de recursos nas trocas. O quarto afirma que o valor é contextual e emergente no uso. O último axioma estabelece que a cocriação de valor é coordenada por instituições e seus arranjos.

O Marketing, permeado pela Lógica Dominada por Serviço, como filosofia de negócios e processo gerencial, deve: a) facilitar a integração de recursos para o fornecimento de serviços e bens; b) subsidiar experiências de consumo em que os beneficiários sejam apoiados para que se engajem e aportem recursos; c) criar a perspectivas de interações e trocas em redes ou ecossistema de serviço; d) visar ao sucesso na cocriação de valor (Bettencourt, Lusch, \& Vargo, 2014). Ecossistema que embute o dinamismo de relacionamentos de trocas diretas e indiretas, em que: i) a forma diádica de troca é expandida para trocas complexas; ii) a rígida separação de 
papéis entre provedores e clientes é substituída pelo conceito genérico de atores; iii) os atores são todos integradores de recursos, via aplicação de competências especializadas e complementares, mirando a cocriação de valor almejada.

Muito há ainda por se fazer, sem dúvida, nos âmbitos da modelagem do sistema de serviço, em particular, e da Ciência de Serviço. Uma recente revisão sistemática da literatura sobre sistema de serviço revelou três grandes direções para futuras pesquisas (Frost \& Lyons, 2017): (1) maior diversidade de esquemas de pesquisa e de abordagens analíticas; (2) novas perspectivas para conduzir um trabalho mais ontológico nos componentes desse sistema; (3) uma melhor compreensão do papel da inovação. A Ciência de Serviço enfatiza a inovação. Para tanto, parte da compreensão dos antecedentes e mecanismos da experiência de serviço, bem como das variáveis intervenientes, tal qual os fatores ambientais. Porém, pela revisão, insta avançar na inovação.

Sob outro prisma, diversas questões pertinentes à Ciência de Serviço têm raízes antigas. Avanços para explicá-las foram se sedimentando ao longo do tempo, sendo este o expressivo acervo de partida dessa Ciência. Um leque dessas contribuições prévias está refletido nas metáforas relacionadas ao serviço (Maglio, 2015): a) o encontro de serviço; b) o momento da verdade; c) a jornada do cliente; d) a linha de frente e os bastidores, e) a fábrica de serviço.

\section{Vanguarda da IBM na Ciência de Serviço}

No movimento de fundação e desenvolvimento da Ciência de Serviço, a IBM tem sido um contribuinte ímpar. Ela acreditou e catalisou essa iniciativa mais do que qualquer outro ente. Atestam isso as publicações de impacto de seus profissionaispesquisadores, notadamente Paul P. Maglio e Jim Spohrer, que inspiraram, segundo Lusch e Vargo (2014), a formulação da Lógica - de cocriação de valor e de troca dominada por Serviço.

Em sintonia, o próprio negócio da IBM se tornou muito mais que a original produção e comercialização de equipamentos (hardware) de informática: reinventouse com a oferta de serviços, sistemas e software, focada em soluções integradas. Nas operações em mais de 175 países, serviços representaram cerca de $46 \%$ do faturamento em 2015; softwares geraram outros 30\% (Marcial, 2017). A companhia lidera o desenvolvimento de inovadoras redes de cocriação de valor, combinando 
recursos de múltiplos atores, elevando substantivamente a eficiência, a qualidade e os resultados de seus beneficiários/clientes.

A tecnologia de computação cognitiva da IBM visa extrair insights e gerar soluções para problemas práticos. Para tanto, emprega algoritmos de inteligência artificial que processam enormes volumes de dados, estruturados e não estruturados (nesse caso, usando linguagem natural, textos e imagens), num sistema ao mesmo tempo multiespecialista e versátil, capaz de aprender, descobrir padrões e, acima de tudo, equacionar problemas.

É o que se encontra nas aplicações do supercomputador Watson da IBM, em hospitais, bancos e outros tantos ramos e organizações (IBM, 2017). Na verdade, o Watson é um sistema cognitivo que compreende, raciocina e aprende, que combina e articula o homem e a máquina. A Marchesa - uma inspiradora marca de alta moda - recorreu aos avançados sensores do Watson para criar um vestido que entende e responde à usuária. O Watson digitalizou vastos volumes de dados sociais de clientes para que o vestido possa mudar de cor em função dos câmbios de sentimento. Mais. O Watson leu e processou mais de 40.000 fontes e ajudou a Marchesa a descobrir materiais que dão vida a seus tecidos. Centenas de vestidos em passarelas de eventos de gala foram analisados pelo Watson, que se tornou o especialista em cores da Marchesa. Nos maiores eventos de moda, o vestido da Marchesa portado por uma estrela acende conforme o tom das mensagens das suas fãs no Twitter. É uma fabulosa cooperação entre seres humanos e máquina arquitetada pela IBM.

No Brasil, a IBM disponibiliza ao banco Bradesco, com o Watson, as capacidades de aprendizado e de processamento de linguagem natural. O Watson identifica e usa corretamente diferentes sotaques em comunicações com gerentes de agências, situados Brasil afora, para tirar dúvidas e prestar orientação. O plano é que, num estágio posterior, o Watson também apoie atendentes humanos do Bradesco junto aos clientes, até em conversas por telefone (Exame, 2016).

A renovação da IBM e sua vanguarda na marcha da Ciência de Serviço avultam uma generalizável, senão generalizada, cadeia de efeitos. É a relação entre a capacidade de inovar e o desempenho empresarial, saliente em uma meta-análise. Rubera e Kirca (2012) constataram que a inovatividade: a) tem efeitos positivos diretos na posição financeira e no valor da empresa; b) afeta indiretamente o valor 
da empresa por meio de efeitos na posição de mercado e na posição financeira. Os resultados ainda sugerem que os impacto da inovatividade na posição de mercado e na posição financeira são mais fortes para as empresas em ramos de alta tecnologia e nas inovações radicais. É uma lição crucial para as empresas e os profissionais menos inovadores.

\section{Brasil e Ciência de Serviços}

O Brasil vive tempos dificílimos. Em termos de geração de riquezas, medida pela variação do Produto Interno Bruto (PIB), o quadriênio de 2014 a 2017 deve findar como o pior da longa série histórica do país. Houve o ínfimo crescimento de $0,1 \%$ do PIB (medido pelo valor adicionado a preços básicos) em 2014, decréscimo de 3,8\% em 2015, decréscimo em 2016 de 3,6\% e estimativa de débil expansão de 0,5\% em 2017 (IBGE, 2017).

Pior ainda, a produtividade do trabalho no Brasil permaneceu relativamente estagnada de 1980 a 2015, após forte aumento entre 1950 e 1980 (Credit Suisse, 2017). Outros países emergentes lograram expansão significativa da produtividade e, se mantido esse desenrolar, eles tendem a superar os trabalhadores brasileiros nesse fator chave. Apesar dos altos e baixos nesses 35 anos, na série completa a variação acumulada foi quase zero (Lamucci, 2017). O pior período foi entre 1981 e 1990, quando a taxa de produtividade no país caiu $2 \%$ ao ano. Nas duas décadas seguintes (de 1991 a 2010), o crescimento acumulado não foi além de 2,8\%. Entre 2011 e 2016 sobreveio nova queda, de 1,1\%. Doravante, arrefecendo o bônus demográfico (aumento do percentual de trabalhadores na população), a melhora da renda per capita no Brasil dependerá mais ainda do incremento dessa produtividade.

Do estudo da gestão com grandes amostras, em empresas de muitos países, Bloom et al (2012): a) vislumbram as variações nas práticas de gestão como importante explicação das grandes diferenças de produtividade entre países e empresas; b) ilustram com o Brasil, ao lado da China e da Índia, a tendência de empresas em países em desenvolvimento serem pobremente administradas.

O domínio da Lógica Dominada por Serviço, como acima apontado, compreende tanto as organizações mais prestadores de serviços quanto aquelas mais fabricantes de bens, além de todas as demais situadas no contínuo entre esses dois extremos. Sem embargo, o Brasil é uma economia genuinamente pós-industrial 
(Bell, 1978), em que o setor serviços responde por bem mais que metade do PIB. Em 2016, o setor gerou $73,3 \%$ do PIB no ano de 2016, ante $21,2 \%$ do setor industrial e meros 5,5\% do setor agropecuário (IBGE, 2017).

Pela combinação das diversas características nacionais acima, a Ciência de Serviço e a Lógica Dominada por Serviço poderia catapultar uma guinada das empresas no Brasil na direção da competividade (de um lado) e da qualidade de vida da população (do outro). Ademais, a LDS preconiza reinterpretar a relação entre os papeis da gestão e do empreendedorismo. Na LDS, o esforço empreendedor é essencial para a criação de valor, sendo as atividades de gestão e de marketing casos especiais. O empreendedorismo é o elemento de que tanto carecem as organizações no Brasil, onde a percepção de infactibilidade tem contagiado tanta gente.

Papel assim relevante foi cumprido, tempos atrás, pelo movimento da Qualidade Total (Campos, 1990), que empolgou e renovou organizações nos quatro cantos do país, imbuídas de valores e dotadas de competências oriundas também do exterior. Foi um tempo fecundo de expoentes como W. Edwards Deming e Joseph M. Juran, dos Estados Unidos, e Kaoru Ishikawa e Yoshio Kondo, do Japão (Goetsch \& Davis, 2015).

Em paralelo, tal qual no exterior (Bitner, Brown, Goul, \& Urban, 2008), no Brasil o esforço de desenvolvimento da Ciência de Serviço precisa ultrapassar as fronteiras da comunidade acadêmica e incorporar empresas privadas, órgãos governamentais, organizações não governamentais e suas respectivas comunidades profissionais. Tais parcerias não são uma capacidade no País, muito pelo contrário. Os benefícios potenciais da Ciência para essas outras partes são um atrativo para conquistar a cooperação delas.

Também hoje muito pertinente ao Brasil, a LDS reconhece o papel central dos beneficiários no sistema de serviço e a precedência do marketing em relação à produção. Implica que, principiando pela missão e a visão, se vai identificar um segmento-alvo, para então definir os benefícios por ele buscados e, fechando o ciclo, projetar e implantar as atividades-meio para produção da proposta de valor, que cada cliente do alvo singularmente cocriará. Tal fluxo é um enorme superação das raízes históricas do Brasil e de suas organizações e empresários (Moog, 1989; Senna, 1995) e de suas manifestações atávicas incessantes. 
A demolição da concepção mercantilista por Adam Smith ao final do século XVIII, com a obra A Riqueza das Nações, é destacada por Senna (1995). Smith evidenciava como a maximização da produção deveria servir ao consumidor, o verdadeiro rei do sistema. Ao contrário, para Senna (p.176) por muito tempo os consumidores brasileiros tiveram de arcar com preços altos demais de mercadorias, em decorrência do protecionismo governamental aos produtores nacionais. Senna comenta a tese de que, nas esferas de governo, os indivíduos usufruem mais espaço para agir conforme suas conveniências, tornando-se "parceiros do rei", não dos clientes. Mas esses não são traços só do passado nacional.

No presente, seguidos escândalos no Brasil trazem vários das maiores empresas no Brasil alinhadas não com os clientes, mas com agentes públicos, mandatários e políticos, numa ecossistema de corrupção reputada até como a maior da história mundial. Possibilidade essa considerada também no exterior, como em longa matéria do prestigiado diário britânico The Guardian (Watts, 2017), que explora os fatos, os males, os antecedentes e os desdobramentos da Operação Lava-Jato. Na reportagem está a imagem do Cristo Redentor empunhando uma arma de fogo em uma das mãos e um saco de dinheiro na outra. Lastimável retrato, a exigir transformação. De novo, a LDS é um marco capaz de conduzir linguagens, protocolos de comunicação, regras, modelos de governança e outras instituições, que viabilizem as trocas de serviço, priorizando a perspectiva dos beneficiários (eficácia) e buscando a sustentabilidade na perspectiva de produtores e da sociedade (eficiência).

\section{Reflexão Final}

$\mathrm{Na}$ órbita da $4^{\mathrm{a}}$ Revolução Industrial, as organizações estarão mais e mais compelidas a repensar seu modelo e sua gestão, tendo as pessoas como pedra angular, alavancando a tecnologia e evoluindo na cultura e nos mecanismos de colaboração, cocriação e inovação (Qiu, 2012). Sem isso, os patamares de custo e qualidade tendem a ficar aquém do exigido pela competividade, constituindo arriscada vulnerabilidade. Tais preceitos, sob a Lógica Dominada por Serviço (LDS), se aplicam às organizações classicamente classificadas como de serviços tanto quanto industriais. 
Tem-se aqui a sincera impressão de que a Ciência de Serviço pode ajudar na transição para um patamar com algo de um 'admirável mundo novo'. Mas mundo oposto ao do homônimo romance distópico de Huxley (2014), sobre a sociedade capitalista, industrial e tecnológica em mais ou menos 2540 D.C, em que "a racionalidade se tornou a nova religião, em que a ciência é o novo ídolo, um mundo no qual a experiência do sujeito não parece mais fazer nenhum sentido, e no qual a obra de Shakespeare adquire tons revolucionários" (Huxley, 2014, Sinopse).

A LDS já compõe, ao menos implicitamente, a filosofia e a gestão de algumas das empresas mais exitosas do Mundo, como a IBM, o Google, a Amazon, a Tesla. São companhias baseadas no conhecimento, marcadas por modelos de negócio e propostas de valor originais e sustentáveis, que instituíram ecossistemas de serviço antes inimagináveis, que mudam estilos de vida, estando na vanguarda da Nova Economia. Ajudar a sistematizar, aprimorar e disseminar essas competências é incumbência da comunidade científica.

A LDS reveste-se das propriedades de uma meta-ideia, que estimula a criação de ideias mais específicas e teorias de médio alcance (Lusch \& Vargo, 2014), por exemplo, acerca do processo de cocriação de valor e do sistema de serviço. A base fértil está nos conceitos e nas premissas genéricas da LDS, que ensejam a explicação e a previsão dos ecossistemas de serviço, a começar por aqueles mais simples e, numa ampliação progressiva, até chegar à visão de um macrossistema. Contudo, árdua é a empreitada a ser cumprida.

Neste ano, refletindo sobre direções futuras prioritárias para a LDS, (Vargo \& Lusch (2017) incorporam o desenvolvimento teórico de instituições e ecossistemas. Instituições e arranjos institucionais que aprimorem a coordenação entre os atores nos ecossistemas de serviço. Essa é uma vertente de suma importância para a administração tanto pública quanto privada no Brasil.

Mas, apesar da auspiciosa potencialidade da LDS e da Ciência de Serviço, o entusiasmo com elas não pode atenuar o espírito crítico. Afinal, o êxito do cientista, reflete Firestein $(2012$, p. 17), requer fé na incerteza, prazer no mistério e o aprendizado do cultivo da dúvida, pois a ciência é sempre uma revisão em andamento. Esses, mais ainda, são os predicados necessários a quem esteja ou venha a somar forças na construção da recentíssima Ciência de Serviços. Valerá, assim, muito a pena. 


\section{Referências}

Banhe, S., \& Polese, F. (2010). Smart service systems and viable service systems: Applying Systems Theory to Service Science. Service Science, 2(1), 21-40.

Basharat, T., Ahmad, H. (2017). Applying service dominant logic perspective: Studying patient care system of Shaukat Khanum Memorial Cancer Hospital (Lahore) and Shouldice Hospital (Canada). Journal of Service Science Research, 9(1), 31-46.

BBC. (2016). 6 exemplos de como usar a computação cognitiva. 2016. Revista Exame. Recuperado em 13, novembro, 2017, de https://exame.abril.com.br/tecnologia/6-exemplos-de-como-usar-computacaocognitiva/.

BBC. (2016). Como o Google ganha dinheiro? BBC Brasil. Recuperado em 13, nov., 2017 de http://www.bbc.com/portuguese/noticias/2016/03/160329_google_dinheiro_fn.

Bell, D. (1978). O Advento da Sociedade Pós-Industrial: Uma tentativa de previsão social. São Paulo, Cultrix.

Bettencourt, L. A., Lusch, R. F., \& Vargo, S. L. (2014). A service lens on value creation: Marketing's role in achieving strategic advantage. California Management Review, 57(1), 44-66.

Bitner, M. Jo, Brown, S. W., Goul, M., \& Urban, S. (2008). Services Science journey: Foundations, progress, and challenges. In B. Hefley \& W. Murphy (Eds.). Service Science, Management and Engineering Education for the 21st Century. (pp. 227233). New York: Springer.

Bloom, N., Genakos, C., Sadun, R., \& Van Reenen, J. (2012). Management practices across firms and countries. Academy of Management Perspectives, 26(1), 12-33.

Campos, V. F. (1990). Gerência da Qualidade Total - Estratégia para aumentar a competitividade da empresa brasileira. Rio de Janeiro: Bloch Editores.

Capelas, B. (2017, abril 16). Impressão 3D está longe das casas, mas já transforma escolas e hospitais. O Estado de São Paulo.

Capell, K., Arndt, M., \& Carey, J. (2005, setembro, 8). O desafio do medicamento personalizado. Newsletter Valor Econômico, 4(880).

Credit Suisse. (2017). Brasil - Cenário Menos Incerto em 2017 e 2018. São Paulo.

Davis, S., \& Botkin, J. (1994). The coming of knowledge-based business. Harvard Business Review, 72(5), 165-70. 
Erl, T., Puttini, R., \& Mahmood, Z. (2013). Cloud Computing: Concepts, technology \& architecture. Upper Saddle River: Prentice Hall.

Firestein, S. (2012). Ignorance: How it drives science. Oxford: Oxford University Press.

Frost, R., \& Lyons, K. (2017). Service systems analysis methods and components: A systematic literature review. Service Science, 9(3), 219-234.

Gotelli, N. J. (2008). A Primer of Ecology (4th ed.). Sunderland: Sinauer Associates.

Goetsch, D. L., \& Davis, S. (2015). Quality Management for Organizational Excellence: Introduction to total quality (8th ed.) Upper Saddle River: Pearson.

Gummesson, E., \& Mele, C. (2010). Marketing as value co-creation through network interaction and resource integration. Journal of Business Market Management, 4(4), 181-198.

Hannan, M. T., \& Freeman, J. A. (1989). Organizational Ecology. Cambridge: Harvard University Press.

Houaiss, A. (2009). Dicionário Houaiss da Língua Portuguesa: Com a nova ortografia da Língua Portuguesa. São Paulo: Objetiva.

Huxley, A. (2014). Admirável Mundo Novo (22a ed.). São Paulo: Biblioteca Azul.

Hsu, C. (2009). Service Science and Network Science. Service Science, 1(2), i-ii.

IBGE (Instituto Brasileiro de Geografia e Estatística). (2017). Indicadores IBGE: Contas Nacionais Trimestrais: Abril / Junho 2017. Rio de Janeiro.

IBM. (2017). Marchesa and Watson worked together to create a dress that thinks. Recuperado em 12, novembro, 2017, de https://www.ibm.com/watson/stories/dress.html.

Katzan Jr, H. (2008). Foundations of service science - management and business. Journal of Service Science, 1(2), 1-16.

Katzan Jr, H. (2009). Principles of service systems: An ontological approach. Journal of Service Science, 2(2), 35-52.

Kellmereit, D., \& Obodovski, D. (2013). The Silent Intelligence - The Internet of Things. New York: DND Ventures LLC.

Kotler, P., \& Armstrong, G. (2015). Princípios de Marketing (15a ed.). São Paulo, Pearson.

Kumar, V. (2015). Evolution of Marketing as a discipline: what has happened and what to look out for. Journal of Marketing, 79(1), 1-9. 
Lamucci, S. (2017, março, 07). Produtividade do trabalho está estagnada desde 1980, diz estudo. Valor Econômico.

Lévi-Strauss, C. (1969). The Raw and the Cooked (Mythologiques, vol. 1). Chicago: University of Chicago Press.

Lyons, K. \& Tracy, S. (2013). Characterizing organizations as service systems.

Human Factors and Ergonomics in Manufacturing \& Service Industries, 23(1), 19-27.

Lusch, R. F., \& Vargo, S. L. (2014). Service-dominant logic: Premises, perspectives, possibilities. Cambridge University Press.

Maglio, P., \& Spohrer, J. (2008). Fundamentals of service science. Journal of the Academy of Marketing Science, 36(1), 18-20.

Maglio, P., \& Spohrer, J. (2013). Service Science 2.0. Service Science, 5(2), 85-86.

Marcial, G. (2017, janeiro, 23). Why transformation at IBM is bearing fruit. Forbes. Recuperado em 21, novembro, 2017 de https://www.forbes.com/sites/genemarcial/2017/01/23/why-transformation-at-ibmis-bearing-fruit/\#3e19b84f4f18.

Microsoft Azure. (2017). What is cloud computing? A beginner's guide. Recuperado em 20, novembro, 2017, de https://azure.microsoft.com/en-in/overview/what-iscloud-computing/.

Moog, V. (1989). Bandeirantes e pioneiros (17a ed.). Rio de Janeiro: Civilização Brasileira.

Perasso, V. (2016). O que é a 4⿳亠丷厂 revolução industrial - e como ela deve afetar nossas vidas. BBC Brasil. Recuperado em 12, novembro, 2017, de http://www.bbc.com/portuguese/geral-37658309.

Qiu, Robin. (2012). Service Science: The foundations of service engineering and management. Hoboken: John Wiley \& Sons.

Rifkin, J. (2014). The Zero Marginal Cost Society - The internet of things, the collaborative commons, and the eclipse of capitalism. London: Palgrave MacMillan.

Rubera, G., \& Kirca, A. H. (2012). Firm innovativeness and its performance outcomes: A meta-analytic review and theoretical integration. Journal of Marketing, 76(3), 130-147.

Sagan, C. \& Kalosh, A. (2006). Bringing science down to earth. In C. Sagan \& A. Kalosh. Conversations with Carl Sagan. (pp. 99-105). Jackson: University Press of Mississippi. 
Sawada, T. (2016, abril, 4). São Paulo ganha laboratórios para fabricar 'quase tudo'. O Estado de São Paulo.

Schwab, K. (2016). The Fourth Industrial Revolution. New York: Penguim Random House.

Senna, J. J. (1995). Os parceiros do rei: Herança cultural e desenvolvimento econômico no Brasil. Rio de Janeiro: Topbooks.

Scott, D. J., Stohler, C. S., Egnatuk, C. M., Wang, H. K., Robert A., Zubieta, J. (2008). Placebo and nocebo effects are defined by opposite opioid and dopaminergic responses. Archives of General Psychiatry, 65(2), 220-231.

Spohrer, J., Anderson, L., Pass, N., \& Ager, T. (2008). Service science and servicedominant logic. Paper \# 2, Otago Forum 2 Academic Papers.

Vargo, S. L., \& Lusch, R. F. (2004). Evolving to a new dominant logic for marketing. Journal of Marketing, 68(1), 1-17.

Vargo, S. L., \& Lusch, R. F. (2016). Institutions and axioms: an extension and update of service-dominant logic. Journal of the Academy of Marketing Science, $44(1), 5-23$.

Vargo, S. L., \& Lusch, R. F. (2017) Service-dominant logic 2025. International Journal of Research in Marketing, 34(1), 46-67.

Watts, J. (2017). Operation Car Wash: Is this the biggest corruption scandal in history? The Guardian. Recuperado de

https://www.theguardian.com/world/2017/jun/01/brazil-operation-car-wash-is-thisthe-biggest-corruption-scandal-in-history.

Wolfson, A., Tavor, D., Mark, S., Sheva, B., Schermann, M., \& Krcmar, H. (2010). $S^{3}$-sustainability and Services Science: Novel perspective and challenge. Service Science, 2(4), 216-224.

Worldmeters. (2017). População Mundial Atual. Recuperado em 21, novembro, 2017 de http://www.worldometers.info/br/.

Zeithaml, V. A., Parasuraman, A., \& Berry, L. L. (1985). Problems and strategies in services marketing. Journal of Marketing, 49(2), 33-46. 